\title{
Building up financial literacy and financial resilience
}

\author{
Annamaria Lusardi ${ }^{1,2} \cdot$ Andrea Hasler $^{3} \cdot$ Paul J. Yakoboski $^{4}$
}

Received: 6 July 2020 / Accepted: 17 July 2020 / Published online: 31 July 2020

(c) Springer-Verlag GmbH Germany, part of Springer Nature 2020

\begin{abstract}
This article uses data from the 2020 TIAA Institute-GFLEC Personal Finance (P-Fin) Index to show that many American families were financially fragile well before the COVID-19 pandemic hit the U.S. economy. Financial fragility is particularly severe among specific demographic groups, such as African-Americans and those with low income. The article also shows that financial fragility is strongly linked to financial literacy and that many Americans are ill-equipped to deal with the financial decisions needed to navigate through a financial crisis. Suggestions are provided to deal with personal finance decisions in times of emergency.
\end{abstract}

Keywords COVID-19 · Financial resilience $\cdot$ Financial education · Personal finance

In January 2020, the unemployment rate in the United States was as low as 3.6 percent, and the stock market was reaching record highs. Mild concerns about cases of an unknown virus notwithstanding, the economy was firing on all cylinders. It was amidst this backdrop that the Global Financial Literacy Excellence Center (GFLEC) and the TIAA Institute conducted the 2020 Personal Finance (P-Fin) Index, an annual survey to assess knowledge and understanding which enable sound financial decision making and effective management of personal finances. A long term project that started in 2017, the P-Fin Index measures financial literacy with 28 questions covering eight functional areas, from earning, consuming, saving, investing, and borrowing/managing debt, to insuring, comprehending risk, and go-to information sources. The survey also collects demographic data, as well as indicators of financial wellness, providing insights into the state of Americans' personal finances.

Annamaria Lusardi

alusardi@gwu.edu

1 The George Washington University, Washington, DC, USA

2 Global Financial Literacy Excellence Center, Washington, DC, USA

3 Global Financial Literacy Excellence Center, The George Washington University School of Business, Washington, DC, USA

4 TIAA Institute, Charlotte, NC, USA 
The results of the survey offer several suggestions to assess the potential effects of the current economic crisis. In the next section, we describe those findings and how they can be used to help families become more financially resilient.

\section{Financial literacy and preparedness before the COVID-19 crisis}

A primary takeaway from the P-Fin Index data is that financial literacy in the United States is quite low. ${ }^{1}$ In 2017, respondents answered an average of 49 percent of the financial literacy questions correctly. Financial literacy has improved only slightly since then, with respondents answering 52 percent of the questions correctly in 2020, which is still a failing grade. Unfortunately, comprehending risk and insuring are the functional areas where knowledge is lowest, which is what matters most in a time of economic turmoil. While respondents could answer 64 percent of the borrowing questions correctly, they correctly answered only 47 percent of the insuring questions and an abysmal 37 percent of the questions on risk. Without a good financial knowledge foundation, it can be difficult to make sound financial decisions in ordinary times. In extraordinary times like the current ones, where risk and uncertainty are amplified, it is even more difficult. As Fig. 1 shows, while knowledge in some topics improved slightly over time, it is not the case for the area where the knowledge is lowest, i.e., comprehending risk.

Also troublesome is the fact that financial literacy tends to be lower among females, lower-income individuals, the unemployed or disabled, the young, and the less educated. Unfortunately, many of these groups are often hit the hardest by economic crises, and lower levels of financial literacy may exacerbate these impacts.

Low financial literacy heading into the pandemic is only part of the picture. The P-Fin Index also indicated that a substantial proportion of the population was already financially vulnerable, even when the economy was doing well. We turn next to indicators of financial fragility and financial resilience, terms that were coined right after the financial crisis of 2007-2008. ${ }^{2}$ To measure whether a respondent is financially fragile, we included the following question in the survey: How confident are you that you could come up with $\$ 2,000$ if an unexpected need arose within the next month? The possible answers to this question are: I am certain I could come up with the full \$2,000; I could probably come up with \$2,000; I could probably not come up with \$2,000; I am certain I could not come up with \$2,000; Don't know. The wording of this question is designed to assess whether respondents could manage a medium-size financial shock. Note that the question does not ask if respondents have $\$ 2,000$ in cash in the bank; respondents are asked whether they could "come up" with such an amount, or, in other words, whether they can access resources in time of need. If respondents answer that they "could probably not" or "certainly not" come up with the money, we classified them as financially fragile. In January 2020, we found that 27 percent of respondents were financially fragile (Fig. 2). If such

\footnotetext{
1 For details about the survey and the findings, see Yakoboski et al. (2020).

2 See Lusardi et al. (2011).
} 


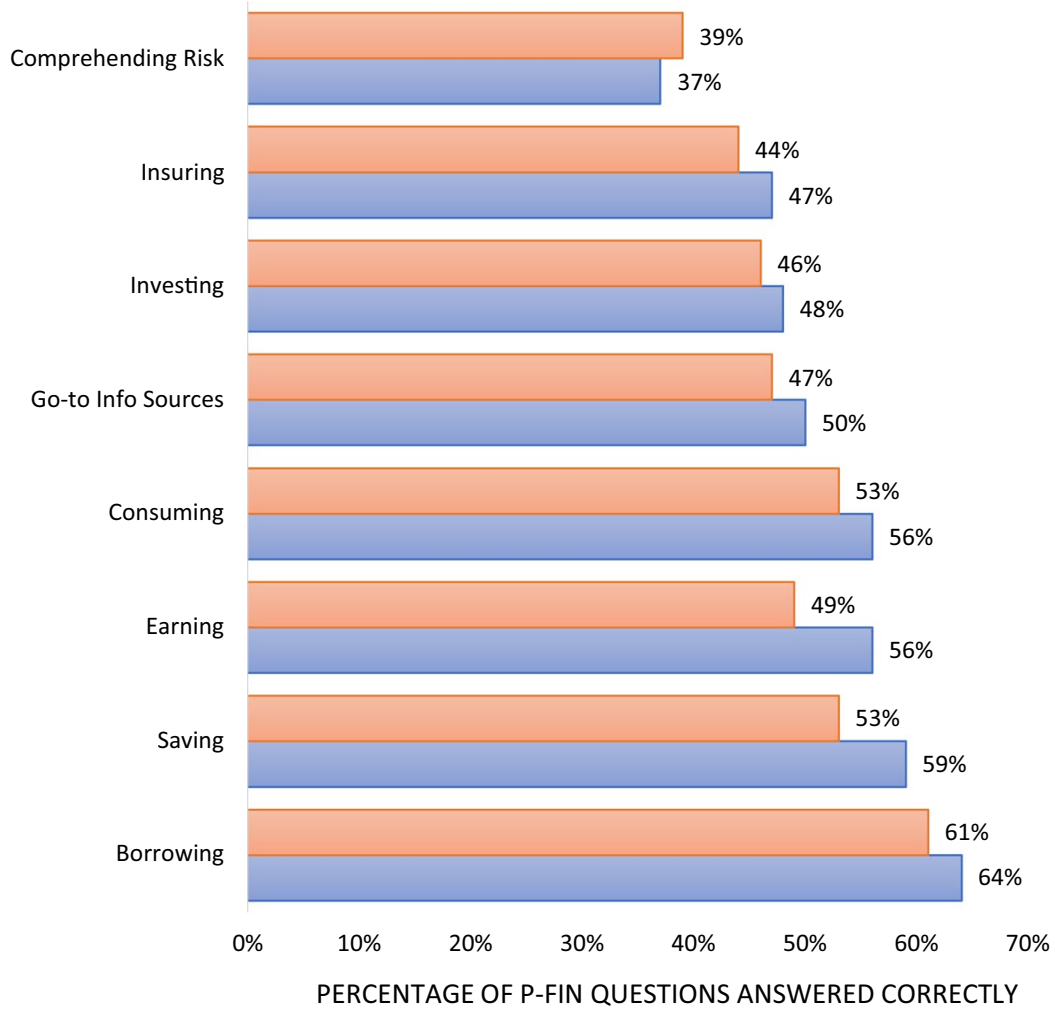

Fig. 1 Financial Literacy by Functional Area in 2017 and 2020. Source 2020 TIAA Institute-GFLEC Personal Finance Index

Cannot come up with $\$ 2,000$ in a month

Find it difficult to make ends meet in a typical month

Feel debt prevents them from adequately addressing other financial priorities

Do not/did not regularly save for retirement (prior to retiring)

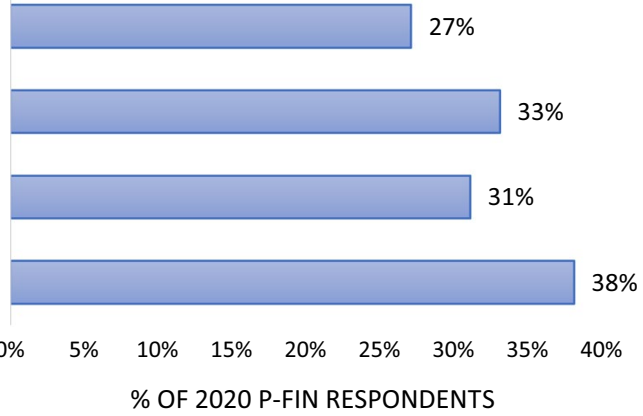

$\%$ OF 2020 P-FIN RESPONDENTS

Fig. 2 Financial Health of Americans in 2020. Source 2020 TIAA Institute-GFLEC Personal Finance Index

a sizeable proportion of Americans had low confidence in their ability to access $\$ 2,000$ when the economy was strong, it should come as no surprise that so many families are under financial distress after losing their paychecks. Without a buffer 


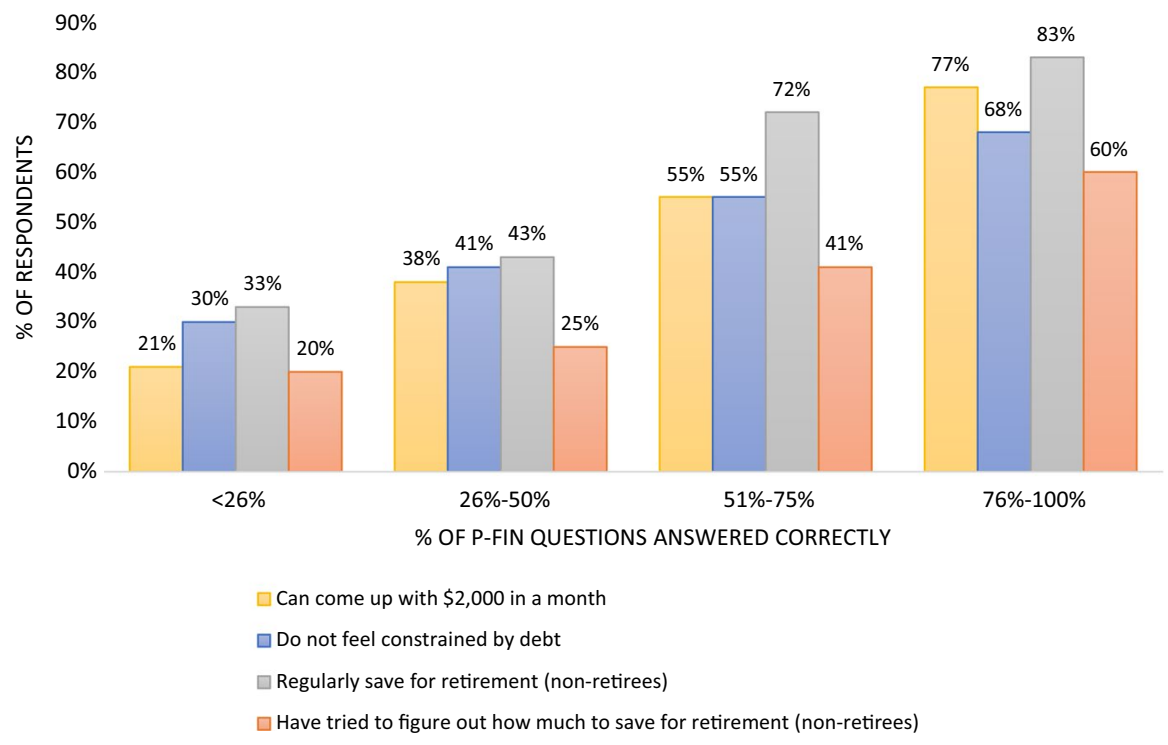

Fig. 3 Financial Resilience by Financial Literacy in 2020. Source 2020 TIAA Institute-GFLEC Personal Finance Index

stock of savings or access to funds, many Americans will have a difficult time navigating through the current crisis.

Other indicators of financial resilience point in the same direction (see Fig. 2). Well before the pandemic hit the economy, one third of respondents in the P-Fin Index reported that they found it very or somewhat difficult to make ends meet. Similarly, 31 percent of respondents felt their debt payments prevent them from adequately addressing other financial priorities, and 38 percent reported that they do not save regularly for retirement. These statistics suggest that even with full employment, a large proportion of Americans was under financial stress and/or unable to save. Being furloughed or laid off during the pandemic will push many families over the edge.

Yet again, disadvantaged groups are more at risk to be financially fragile. According to the 2020 P-Fin Index, about half of African-Americans and almost one third of women were considered financially fragile, compared to only 21 percent of white respondents and 23 percent of men, confirming previous findings from P-Fin data focusing on African-Americans. ${ }^{3}$ Those with less education and lower incomes were also at higher risk of being financially fragile. These are precisely the groups that have been hit the hardest by the COVID-19 crisis. Focusing on these groups is an urgent priority, if we are to mitigate the effects of this crisis.

The 2020 P-Fin Index data shows that financial resilience is strongly associated with financial literacy (see Fig. 3). While only about one in five of the least

\footnotetext{
3 See Yakoboski et al. (2019).
} 
financially literate respondents (those who answered less than 26 percent of the P-Fin questions correctly) claimed that they could come up with $\$ 2,000$ in one month, over three fourths of the most financially literate (those who answered 76 percent or more of the P-Fin questions correctly) were able to face such a shock. Similarly, increased financial literacy is associated with a lower likelihood of feeling constrained by debt. Less than one third of the least financially literate respondents were unconstrained by their debt, compared to two thirds of the most financially literate respondents.

Financial literacy is also correlated with planning for the future, as the financially literate are more likely to save and plan for retirement (see Fig. 3). Just one third of the least financially literate non-retirees regularly save for retirement (vs. 83 percent of the most financially literate non-retirees), and only one fifth of them have tried to determine how much they need to save for retirement (vs. 60 percent of the most financially literate non-retirees).

Previous studies show that the relationship between financial literacy and financial outcomes tends to hold even after controlling for confounding variables, such as income and education. ${ }^{4}$ Thus, the data shows us that with the economy at full employment, those with less financial knowledge are already at risk of falling into financial distress and this can have consequences both in the short term and the long term.

Today, of course, the health and personal finances of Americans have been ravaged by COVID-19. The official unemployment rate soared to 14.7 percent in April, the highest since the Great Depression; the unemployment rate has declined somewhat in subsequent months but remains above 10 percent. The economic fallout of the pandemic has exposed and exacerbated the financial fragility of millions of Americans, as many find that their precautionary savings are insufficient to cover their bills in the absence of a paycheck. This is a painful situation but not a surprising one considering the proportion of people that demonstrated a lack of financial resilience before the crisis.

As a society, we now know that we will need to better prepare for the next crisis. An important step in building a more resilient society is to make financial literacy a reality for all. Financial literacy programs should also diversify content to include understanding and managing risk, as well as developing financial resiliency. Direct financial assistance from the government is clearly part of the solution to this crisis, but in today's economy, people are expected to make many financial decisions affecting their finances now and far into the future. The cost of widespread financially illiteracy to individuals and society is simply too high for us to choose not to invest in financial education.

\footnotetext{
${ }^{4}$ See Lusardi and Mitchell (2014).
} 


\section{A resource hub to manage personal finances in times of a crisis}

Given these findings and the difficulty in managing finances during a pandemic, providing financial advice could offer some help. Guided by the data collected via the P-Fin Index since 2017, GFLEC has built a resource hub for people seeking information and financial advice during this crisis. It is available here: https://gflec.org/ education/financialresilience/, and it provides ten suggestions for managing money during this pandemic as well as links to government, nonprofit, and media articles to help people through these turbulent times. The resources included can help users, for example, to create a budget, learn how to rebuild savings, monitor their credit, manage debt, and use online technology to make financial decisions.

Also included is a wealth of information on government policies enacted in response to the pandemic, including stimulus checks, lower interest rates, and forbearance options. Each of the suggestions is shown as a snapshot in Fig. 4, and the resources provided are being updated on a regular basis. It is our hope that these

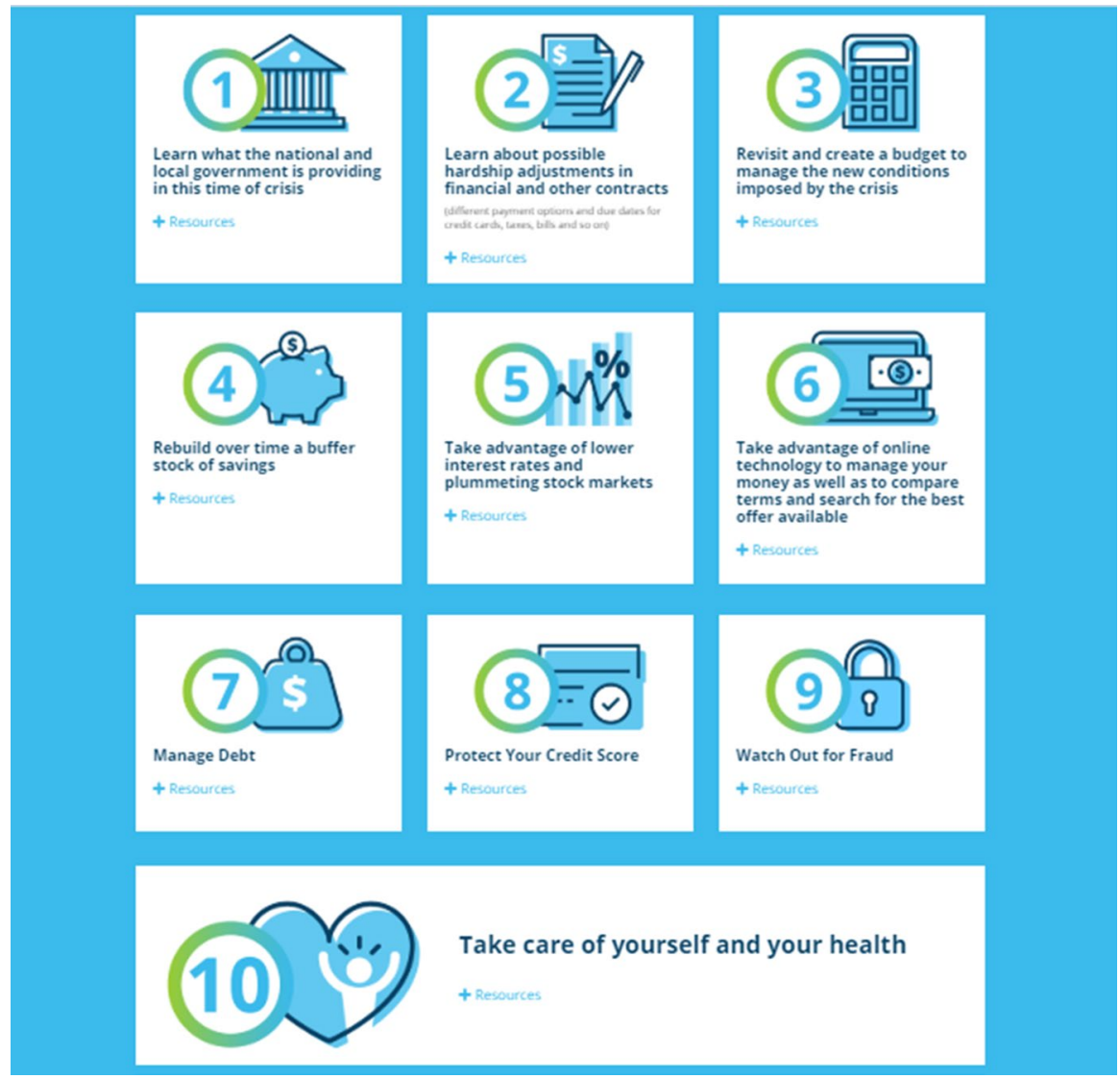

Fig. 4 GFLEC Financial Resilience Hub 
resources and strategies will provide some help and information for people who are overwhelmed by the economic fallout of this crisis and do not know where to turn for assistance.

Acknowledgements We thank Nikhil Yagnik for excellent research assistance. All errors are our own. The TIAA Institute-GFLEC Personal Finance Index is not a publicly available dataset.

\section{Compliance with ethical standards}

Conflict of interest On behalf of all authors, the corresponding author states that there is no conflict of interest.

\section{References}

Lusardi A, Mitchell O (2014) The economic importance of financial literacy: theory and evidence. J Econ Lit 52(1):5-44

Lusardi A, Schneider D, Tufano P (2011) Financially fragile households: evidence and implications. Brookings Papers on Economic Activity, Spring 2011, pp 83-134

Yakoboski P, Lusardi A, Hasler A (2019) Financial literacy and wellness among African Americans. New insights from the Personal Finance (P-Fin) Index. TIAA Institute and the Global Financial Literacy Excellence Center Special Report (October 2019)

Yakoboski P, Lusardi A, Hasler A (2020) The 2020 TIAA Institute-GFLEC Personal Finance Index. Many Do Not Know What They Do and Do Not Know. TIAA Institute and the Global Financial Literacy Excellence Center Special Report (April 2020)

Publisher's Note Springer Nature remains neutral with regard to jurisdictional claims in published maps and institutional affiliations. 